УДК 621.396

\title{
К.О. Споришев
}

Харківський університет Повітряних Сил ім. І. Кожедуба, Харків

\section{ВПЛИВ ЗАКОНІВ ФОРМУВАННЯ КРОКУ КВАНТУВАННЯ НА ПЕРЕШКОДОЗАХИЩЕНІСТЬ СИСТЕМИ ПЕРЕДАЧІ ДАНИХ}

\begin{abstract}
Проведено аналіз існуючих методів квантування сигналів, розглянуті закони формування кроку квантування і їхній вплив на перешкодозахищеність систем передачі даних.
\end{abstract}

Ключові слова: імпульсно-кодова модуляція, нелінійне квантування, перешкодозахищеність, помилка квантування.

Постановка проблеми. Серед проблем, що стоять перед сучасною радіоелектронікою, однією 3 основних $\epsilon$ підвищення ефективності радіотехнічних систем $[1,2]$. Обробка аналогових i цифрових сигналів може виконуватися аналоговим, дискретно-аналоговим i цифровим методами. Аналоговий метод обробки має більшу швидкодію й дає результат у безперервній аналоговій формі. Процес цифрової обробки складається 3 послідовного виконання великої кількості операцій, що ускладнює досягнення високої швидкодії. Цифрова обробка, в порівнянні 3 аналоговою, забезпечує підвищення точності, перешкодозахищеності i стабільності, а також дозволяє виконувати нові, більше складні, види обробки. При цифровій обробці існує проблема наявності шумів квантування.

Метою статті $\epsilon$ визначення впливу шумів квантування на перешкодостійкість системи передачі даних. Оцінка перешкодостійкості військових систем передачі інформації $\epsilon$ досить важливою задачею 3 урахуванням «цінності» інформації, що циркулює в цих системах. Втрата чи викривлення інформації може привести до не виконання підрозділом поставлених завдань або втрати боєздатності.

\section{Основний матеріал}

Найбільш простим алгоритмом цифрового перетворення є ІКМ (імпульсно-кодова модуляція) [4]. При ІКМ, як і при інших видах аналогоцифрового перетворення, реалізуються наступні операції: обмеження спектра; дискретизація в часі; квантування дискретних відліків; подання відліків у вигляді бінарних слів.

У процесі квантування відлік аналогового сигналу рівняється 3 набором граничних рівнів. Якщо відлік попадає в певний амплітудний інтервал, то йому надається значення фіксованого рівня квантування, що відповідає даному інтервалу. У цифровій системі кожному квантованому відліку ставиться у відповідність двійкова кодова комбінація, при цьому чим більше рівнів квантування тим більш довга ця комбінація. Для оцінки необхідних швидкостей передачі цифрових потоків, отриманих дискретизацією із частотою Котельникова-Найквиста, можна скористатися визначенням обсягу переданої інформації I [3]:

$$
I=2 K f_{2} p, \text { Мбит/с, }
$$

де $K$ - розряд кодування; $f z p$ - гранична частота спектра сигналу, МГц.

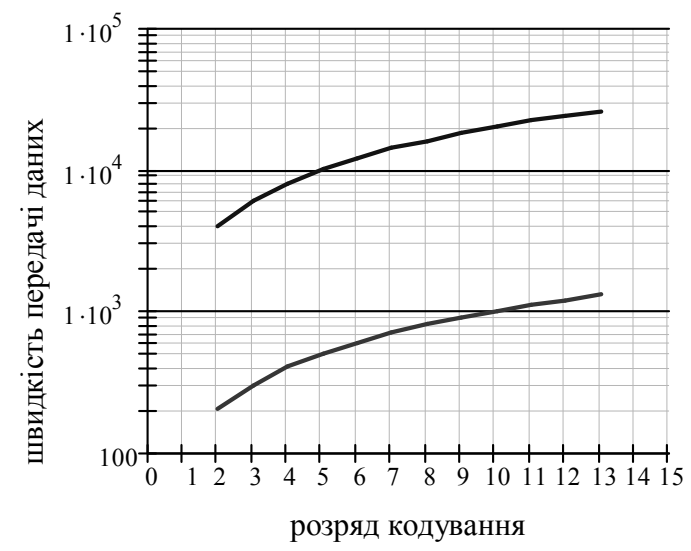

Рис. 1. Залежність швидкості передачі інформації від кількості розрядів кодування

При IKM із безперервного сигналу 3 безперервною амплітудою створюється цифровий сигнал, що складається 3 n-бітових блоків, причому кожний n-й біт містить амплітуду модульованого імпульсу. Після одержання сигналу процес повторюється у зворотній послідовності 3 метою відновлення аналогового сигналу. У процесі IКМ порушуються умови теореми про дискретне подання. Внаслідок оцифровування модульованого імпульсу вихідний сигнал $\epsilon$ тепер тільки апроксимацією й не може бути відновлений точно. Цей ефект відомий як помилка квантування або квантовий шум. Відношення сигнал/шум для квантового шуму становить [3]:

$$
S N R_{Д Б}=20 \lg 2^{n}+1,76 \partial Б=6,02 n+1,76 \partial Б .
$$


Отже, кожний додатковий біт, що використовується для оцифровування, збільшує відношення сигнал/шум приблизно на 6 дБ або в 4 рази.

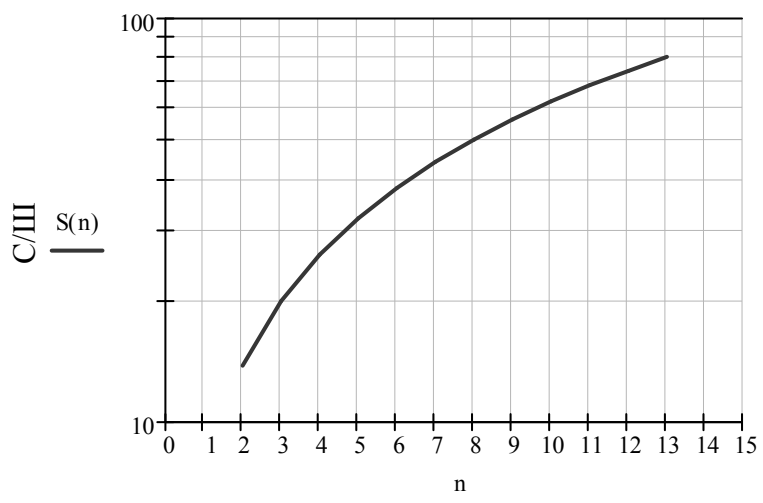

кількість рівней квантування

Рис. 2. Вплив кількості рівнів квантування на відношення сигнал/шум для квантового шуму

Поліпшують ІКМ за рахунок схеми, відомої, як нелінійне кодування, що означає нерівномірне розміщення рівнів квантування. Використання рівномірного розміщення невигідно тим, що середня абсолютна помилка для кожної вибірки однакова, у незалежності від рівня сигналу. Отже, значення 3 меншою амплітудою спотворюються порівняно сильніше. Якщо ж для сигналів 3 низькими амплітудами використати більшу кількість рівнів квантування, а для сигналів з більшими амплітудами - меншу кількість рівнів, то можна досягти помітного зниження рівня викривлень сигналу. Того ж результату можна домогтися, використовуючи й квантування 3 постійним кроком. На вході компандера ефект полягає в стиску вибірки, так що більші значення зменшуються щодо менших. Таким чином, при фіксованій кількості рівнів квантування сигналам низького рівня виділяється більше рівнів. На виході компандер розширює вибірки, і стислій величині відновлює вихідне значення. Нелінійне кодування може значно поліпшити відношення сигнал/шум IКМ. Для мовних сигналів, наприклад, можна одержати поліпшення від 24 до 30 дБ [3]. Кількість рівнів квантування, якої достатньо для цифрового кодування цих значень, обмежена, що спричиняє виникнення викривлень при декодуванні. Ці викривлення одержали назву шумів квантування і $€$ неминучими при використанні ІКМ. Якщо всі кроки квантування вибрати однаковими, більші значення амплітуди будуть відтворюватися більш точно, ніж малі значення, що, відповідно, дає менше значення шумів. У результаті співвідношення сигнал/шум буде сильно залежати від амплітуди сигналу. Зазначений недолік можна перебороти, застосовуючи нелінійне кодування. У цей час у Європі використається нелінійна А-характеристика компандування, що викладена докладно в рекомендації МСЭ-Т G.711 [2].

При ІКМ зберігається можливість неспотвореної передачі навіть при малому співвідношенні сигнал/шум, а також те, що з'являється можливість розширення смуги частот абонентського сигналу. При IКМ перетворенні широкосмугових аналогових сигналів (каналів радіомовлення або відеосигналів) можлива наступна альтернатива: або збільшити кількість рівнів квантування й, тим самим, збільшити швидкість передачі зазначеного каналу, або при збереженні стандартної швидкості передачі погіршити якість передачі.

При лінійному квантуванні значення округлення амплітуди однаково для будь-якого рівня сигналу, що надходить на вхід кодера. Таким чином, слабкий сигнал 3 малим рівнем піддається такому ж округленню, як і сигнал з високим рівнем. Тим самим викривлення слабких сигналів здійснюється більше, ніж сильних сигналів. Внаслідок цього перешкодозахищеність сигналів 3 малим рівнем нижче, ніж у сигналів 3 високим рівнем амплітуди. По статистиці сигнали з високим рівнем зустрічаються набагато рідше сигналів 3 малим рівнем, то при кодуванні сигналів лінійне квантування не застосовується. На практиці застосовують нелінійне квантування, при якому ступінь округлення сигналу залежить від величини сигналу, що підлягає кодуванню.

На відміну від лінійного квантування для сигналів 3 різними рівнями перешкодозахищеність залишається постійною. Це досягається за рахунок нелінійної зміни кроку квантування залежно від рівня сигналу. Так, для малих сигналів крок квантування менше, ніж для більших. Тим самим менше округлення, a, отже, вище перешкодозахищеність. Теоретично доведено, що перешкодозахищеність буде постійною для сигналів 3 різними рівнями у випадку, якщо крок квантування буде змінюватися за логарифмічним законом [2].

Для нелінійного квантування МККТТ рекомендує використати два способи формування кроку квантування:

- формування кроку квантування по А-закону;

- формування кроку квантування по $\mu$-закону.

У цих двох способах крок квантування змінюється по квазілогарифмичному закону. Відмінність полягає в тому, що при квантуванні по А-закону крива функції співпадає 3 початком координат по дотичній, а при квантуванні по $\mu$ закону логарифмічна функція приведена до початку координат. А-закон застосовується для систем передачі, що працюють у Європі, а $\mu$-закон - для систем передачі, що працюють в Америці (РСМ24) [2]. 
Для математичного оцінювання процесу квантування доцільно скористуватися наступними виразами [5]:

$$
\varepsilon_{\kappa B}(t)=S_{\kappa B}(t)-S(t),
$$

де $\varepsilon_{\kappa \varepsilon}(t)$ - величина шуму квантування; $\mathrm{S}_{\kappa \varepsilon}(t)$ квантоване значення сигнальної функції; $\mathrm{S}(t)$ значення сигнальної функції.

Величину шуму квантування можливо оцінити за формулою (1). По відношенню до множини сигналів на вході кодера шум квантування можна вважати стаціонарним ергодичним випадковим процесом. При рівномірному розподілі миттєвих значень шуму квантування рівень квантування доцільно розташовувати посередині між границями відповідного даному рівню відрізку. При цьому максимальна похибка не перевищує половини шагу квантування:

$$
-\frac{\delta_{\kappa \beta}}{2} \leq \varepsilon_{\kappa в} \leq \frac{\delta_{\kappa \beta}}{2},
$$

де $\delta_{\kappa в}-$ величина шага квантування.

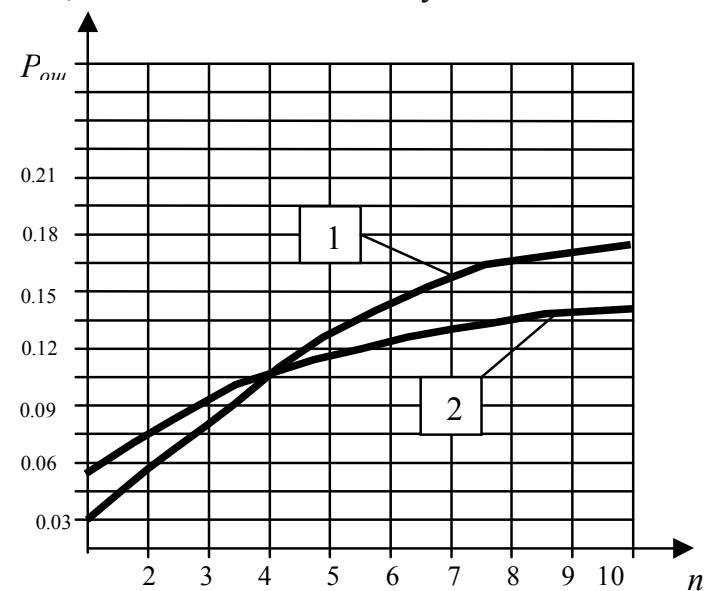

Рис. 3. Залежність імовірності похибки прийому сигналу від кількості рівнів квантування (1 -при логарифмічному законі розподілу рівня квантування; 2 - при лінійному законі розподілу рівня квантування)

При лінійному квантуванні потужність шуму квантування не залежить від закону розподілу квантованого сигналу, а визначається тільки величиною шага квантування:

$$
\varepsilon_{\kappa B}^{2}=\frac{\delta_{\kappa B}^{2}}{12} .
$$

На основі отриманого співвідношення можна зробити ряд висновків. Для обраного шагу квантування кількість рівнів квантування п оцінюється за формулою (4):

$$
n=\frac{S_{\max }-S_{\min }}{\delta_{\kappa 8}}+1 .
$$

Шуми квантування завжди мають місце в системі передачі даних i ï величина визначає точність роботи системи. При виборі шагу квантування необхідно задовольнити суперечливі вимоги підвищення точності роботи системи 3 квантуванням і підвищення перешкодостійкості сигналів.
Це протиріччя можливо вирішити досягненням необхідної перешкодозахищеності шляхом підсилення сигналу, при відповідному забезпеченні шагу квантування, який забезпечує допустиму величину імовірності похибки прийому квантованого значення сигналу:

$$
P_{u y \kappa}=P\left[|n(t)| \geq \frac{\delta_{\kappa \beta}}{2}\right]=\int_{-\frac{\delta_{\kappa \beta}}{2}}^{\frac{\delta_{\kappa \beta}}{2}} \varphi(n) d n,
$$

де $\varphi(n)$ - щільність розподілу миттєвих значень стаціонарної перешкоди $\mathrm{n}(\mathrm{t})$.

\section{Висновки}

Таким чином, у статті розглянуто деякі питання оцінювання впливу шумів квантування на перешкодостійкість військових систем передачі даних. Встановлено, що: по відношенню до множини сигналів на вході кодера шум квантування можна вважати стаціонарним ергодичним випадковим процесом; при рівномірному розподілі миттєвих значень шуму квантування рівень квантування доцільно розташовувати посередині між границями відрізку відповідного даному рівню, при цьому максимальна похибка не перевищує половини шагу квантування; при лінійному квантуванні потужність шуму квантування не залежить від закону розподілу квантованого сигналу, а визначається тільки величиною шага квантування. Запропоновано практичні рекомендації щодо підвищення точності роботи системи передачі даних 3 квантуванням. Показано, доцільність подальших досліджень в галузі розробки нових методів цифрових перетворень, а саме застосування нелінійного квантування для зменшення шуму квантування i як наслідок збільшення загальної перешкодостійкості системи передачі даних.

\section{Список літератури}

1. Воронков Ю. В. Применение микропроцессоров в устройствах приема и обработки сигналов / Ю. В. Воронков. - Н. Новгород : НГТУ, 1993. - 189 с.

2. Мурадов С.Г. Цифровая телефония / С.Г. Мурадов, В.Ю. Журавлев. - М.: ИПК МТУСИ, 2001. - 50 с.

3. Столингс В. Беспроводные линии связи и сети / В. Столингс. - М. : Изд. дом «Вильямс», 2003. - 640 с.

4. Микроволновые технологии в телекоммуникационных системах. - М.: ФГУ ГНИИ ИТТ "Информика", 2005. $-560 \mathrm{c}$.

5. Скляров В.С. Математические модели информационных систем / В.С. Скляров. - X. : ХВВКИУРВ, 1989. -480 c.

Надійшла до редакиії 15.10.2009 p.

Рецензент: д-р техн. наук, доцент I.В. Рубан, Харківський університет Повітряних Сил ім. І. Кожедуба, Харків. 


\title{
ВЛИЯНИЕ ЗАКОНОВ ФОРМИРОВАНИЯ ШАГА КВАНТОВАНИЯ НА ПОМЕХОЗАЩИЩЕННОСТЬ СИСТЕМЫ ПЕРЕДАЧИ ДАННЫХ
}

\author{
К.О. Спорышев
}

Проведен анализ существующих методов квантования сигналов, рассмотрены законы формирования шага квантования и их влияние на помехозащищенность систем передачи данных.

Ключевые слова: импульсно-кодовая модуляиия, нелинейное квантование, помехозащищенность, ошибка квантования.

\section{INFLUENCE OF LAWS OF STEP OF QUANTUM FORMING ON NOISE IMMUNITY OF THE DATA COMMUNICATION SYSTEM}

\author{
K.O. Sporyshev
}

The analysis of existent methods of quantum of signals is conducted, the laws of quantum step forming and their influence, noise immunity of the data communication systems are considered.

Keywords: pulse-code modulation, nonlinear quantum, noise immunity, quantization error.

\section{УДК 621.77}

С.Н. Беляев, А.Е. Истомин

Национальный технический университет «Харьковский политехнический институт»

\section{МЕТОДИКА КОМПЕНСАЦИИ ДРЕЙФА НУЛЯ И МОДЕЛИРОВАНИЕ ШУМОВ МИКРОМЕХАНИЧЕСКОГО ГИРОСКОПА ИНЕРЦИАЛЬНОГО ИЗМЕРИТЕЛЬНОГО БЛОКА}

В статье приводится методика компенсаџии дрейфа нуля сигнала микромеханического гироскопа, а также получена авторегрессионная модель шумов измерений датчика ADIS 16250.

Ключевые слова: бесплатформенная инерциальная система, микромеханический гироскоп, дрейф нуля, формирующий фильтр.

\section{Введение}

Анализ последних исследований и публикаций. $\mathrm{B}$ статьях $[1,2]$ исследуется возможность синтеза системы наведения и стабилизации вооружения легкобронированной боевой машины на основе бесплатформенной инерциальной системы (БИС). БИС используются для определения ориентации и навигации подвижных объектов из-за отсутствия дорогостоящей гироплатформы и достаточно высокой точности. Основой бесплатформенной системы является инерциальный измерительный блок (ИИБ), в состав которого обычно включают три датчика угловой скорости и три линейных акселерометра, расположенные по связанным осям

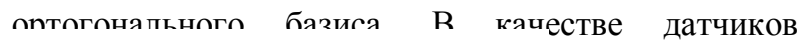
(C) С. Н. Беляев, А. Е. Истомин ззуют лазерные, волоконно-оптические или микромеханические (MEMS) гироскопы.

Для экспериментальной отработки алгоритмов наведения и стабилизации боевого модуля ЛБМ на кафедре колесных и гусеничных машин имени А. А. Морозова НТУ «ХПИ» был собран ИИБ на MEMS-датчиках, в состав которого включены три ДУС ADIS 16250 фирмы Analog Devices [3] и трехосевой акселерометр MMA 7260Q фирмы FreeScale [4].

\section{Постановка задачи}

Анализ публикаций по разработке систем ориентации и навигации на MEMS-датчиках показывает необходимость синтеза фильтра Калмана для успешного решения поставленных задач, а также необходимость предварительной фильтрации сигналов датчиков [5]. Как известно, для синтеза фильтра Калмана необходимо получить ковариационные матрицы шумов процесса и измерений, т.е. нужно иметь модель процесса. Получение адекватной модели зашумленного выходного сигнала ДУС ADIS 16250 и является целью данной статьи. 